\title{
الجملة الاسمية في سورة النور من القرآن الكريم و معانيها
}

\section{AHMAD SEHRI BIN PUNAWAN, MUHAMMAD NUR HIDAYAT}

\author{
Institut Agama Islam Negeri Palu, Indonesia \\ Jl. Diponegoro No. 23, Kec: Palu Barat, Kota Palu, Sulawesi Tengah, 94221, Indonesia \\ Corresponding E-mail: ahmadsehribp@gmail.com
}

\begin{abstract}
The research aims to analyse jumlah ismiyah or mubtada' khabar in surah An Nur. The research focuses at which ayah was contained jumlah ismiyah or mubtada khabar, and how was I'rab, meanings, and tafsir of ayat at surah An Nur. The research is literature review. The result shows there was 48 ayat contained Jumlah Ismiyah or Mubtada' Khabar.
\end{abstract}

Key Words: Surah An Nur, Jumlah Ismiyah, Mubtada' Khabar.

\begin{abstract}
Abstrak
Penelitian ini bertujuan untuk menganalisis jumlah ismiyah atau mubtada' khabar pada surah An Nur. Adapun yang menjadi focus penelitian ini adalah ayat-ayat mana saja yang merupakan jumlah ismiyah atau mubtada' khabar, dan bagaimana I'rab, makna serta tafsir ayat-ayat tersebut. Penelitian ini merupakan penelitian kajian pustaka. Adapun hasil penelitian ini menunjukan terdapat 48 ayat yang mengandung jumlah ismiyah atau mubtada' khabar.
\end{abstract}

Kata Kunci: Surah An Nur, Jumlah Ismiyah, Mubtada’ Khabar. 
تقديرا يحتاج إلى علم النحو.ولذالك يكون علم

النحو احدى من العلوم المهمة في علوم اللغة العربية.

كما عرفنا إن أقسام الكلام في اللغة العربية

هي : الإسم، الفعل, و الحرف. وتنقسم الجملة إلى

قسمين : الجملة الفعلية التي تتكون من الفعل و

الفاعل و مفعول به. و الجملة الاسمية وهي كل واحدةٍ منها مركبة من اسمين، أوّلها مبتدأ والثاني خبرٌ 5. المبتدأ اسم مرفوع يقع في أول الجملة. والخبر هو ما يمكل م معنى المبتدأ، أي هو الجزء الذي ينتظم منه مع المبتدأ جملة مفيدة. وكل جملة تتركب من مبتدإ و خبر تسمى جملة اسمية. نحو : المُدَرُِِّ حَاضِرٌ. ولذلك يريد الباحث أن يعرف إعرابها و معانيها التي كانت في سورة النور من القرآن الكريم إجمالا و تفصيليا.

اختار الباحث سورة النور لأن فيها كثير من

الجملة الاسمية و مثيرة للاهتمام للبحث. أما المشكلات التي يقدمها الباحث فهي ما يلي: (1) ما هي الآيات التي تتركب من الجملة الاسمية في سورة النور؟ (2) ما الإعراب و المعاني أي تفسير

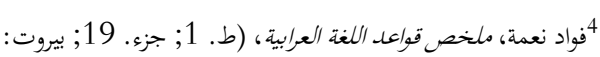

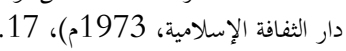
5علي الجارم و مصطفى أمين، النحو الواضح في قواعد اللغة العربية

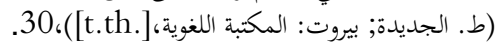

القرآن و العربية كلمات لا يمكن فصل أحدهما عن الأخرى. فدراسة اللغة العربية وتعمقها هي شرط مطلق لفهم القرآن، ودراسة القرآن هي دراسة اللغة العربية بالطبع.

كما ذكرنا سابقا أن من يريد أن يفهم القرآن يحتاج إلى اللغة العربية، لأنه أنزله الله بلسان عربي مبين، وهذا يقتضى أن يُتْتِنَ في جميع نواحى هذه اللغة في الألفاظها و اشتقاقاتها دلالاتها و أساليبها و إعرابها. فينبغي للدارسين أن يعرفوا علوم اللغة العربية، منها البلاغة، الصرف و النحو ، و غيرها. فالبلاغة بمعني الكلام البليغ أي الأدب. واصطلاحا ثلاثة أقسام : المعانى و البيان و البديع. 1 والصرف هو العلم يبحث عن الكلم من حيث ما يعرض له من تصريف و إعلال و إدغام و إبدال به نعرف ما يجب عليه بنية الكلمة قبل انتظامها في الجملة2 والنحو يعني، أول ما يعني، بالنظر في أواخر الكلم، وما يتعبرها من إعراب و بناء، كما يعني بأمور أخرى على جانب كبير من الأهمية. 3 وقيل قواعد يعرف بها وظيفة كل كلمة داخل الجملة، وضبط أواخر الكلمات، و كيفية إعرابها.4 4 و لمعرفة إعراب الكلمة في القرآن الكريم لفظا او

\footnotetext{
1 1عبده عبد العزيز قلقيلة، معجم البلاغة العربية نفد و نقص (ط. 1.; 1. القاهرة: دار الفكر العربى، 1991 1991)، 7.

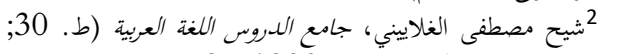

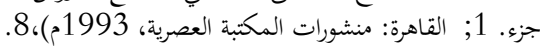

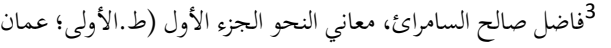
: دار الفكر، 2000 م)، 5 :
} 
Al Bariq : Jurnal Pendidikan Bahasa Arab, 2, (1), 2021, 63-77

مبتداء و خبر، نحو: إن الباطل محذولٌ، لا ريب فيه، ما أحد مسافرًا، لا رجلٌ قائمًا. 6 و قيل الجملة الاسمية وهي التي تبدأ باسم أو بضمير، مثل: العلم

$$
\text { نور، نحن مجاهدون. }
$$

استنادا على التعريف عند النحويين الذي ذكره

في السبق، يمكن أن نستنتج أن الجملة الاسمية هي ترتيب الكلمة التي تبدأ باسم، بعبارة أخرى، يسمى بالإسم الذي يسبقه بالمبتدأ. 8 أو بعبارة أخر، بأن الجملة الاسمية هي تركيب يتكون عن المبتدأ و الخبر، مثلا: أجمد طبيبُ، الطفل يبكي. يتكون الجملة الاسمية عن المبتدأ و وئ الخبر، فلذالك يوجد الجملة الاسمية عنصران هما المبتدأ و الخبر.نظرا من الشرح السابق، أن وجود المبتدا و الخبر في الجملة الاسمية هي مهما جدا.

\section{1}

المبتدأ هو اسم مرفوع متحدث عنه، وقع غالبا في أول الجملة ، وقد يتأخر فيها. 9 وكل واحدة منها اسم مرفوع في أول الجملة خال من عامل لفظى أصيل و بعده كلمة تتمم المعنى الأساسى للجملة : أي تتضمن الحكم بأمر من الأمور لا يمكن أن تستغنى الجملة عنه في إتمام معناها الأساسى ، كالحكم على الشموس بالتعدد ، و وعلى

Bahasa Arab dan Nahwu (Yogyakarta: CV.Bina Usaha, 1985), 85.

9 "سليمان فياض، النحو العصرى دليل مبسط لقواعد اللغة
التي تتركب الجملة الاسمية من الآيات في سورة النور؟

إن لكل كتابة البحث أهداف و فوائد و هكذا أيضا بهذه الرسالة التي يبحث الجملة الاسمية في سور النور و معانيها. والهدف الذي يراد الوصول إليه: (ا) معرفة الجملة الاسمية في سور النور. (ب) معرفة الإعراب و المعاني أي تفسير التي تتركب الجملة الاسمية من الآيات في سورة النور.

وفوائد البحث فتشتمل على ثلاثة أمور: (1) للقارئ: ليتعمق المتعلمون اللغة العربية في توسيع علومهم اللغوية إيقاظ حماستهم في تعلم هذه اللغة، لأنها لغة كاملة و علومها واسعة. (ب) للباحث: فإن هذه الرسالة مفيدة لتوسيع معارفها عن اللغة العربية وتطبيق تلك المعارف القليلة في رسالة عملية ببسيطة. (ج) للجامعة: لإسهام الأفكار لجامع مرجعا من المراجع الأدبية في جانب لزيادة الكتب المطلوبة للمصادر في مكتبة الجامعة و أن يكون هذا البحث نافعا و مرجعا أولا للباحثين الأخرين الذين عن الجملة الاسمية في سورة النور.

الجملة الاسمية - - الجمة الجملة الاسمية هي ما كانت مؤلفة من المبتدأ و الخبر، نحو : الحق منصوزٌ، أو مما أصله

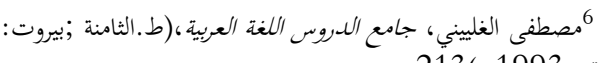
المكتبة العصرية، 1993 م) م) ملفيني، 7t.p] قواد نعمة، ملخص قواعد اللغة العربية،(ط. الأول) 26 (م2015[t.t]; 8 M.yahya Harun dan Aly abu bakar basalamah, Metode Mudah untuk Mempelajari
} 
يلتزم تقديم المبتدأ في أربعة مواضع : (الأول) أن يكون من الألفاظ التي لها لصدارة وهي أسماء الاستفهام و الشرط و التعجيية و كم الخيرية وضمير الشأن وما اقترن بلام الإبتداء والموصول إذا اقترن خبره بالألفاء نحو: من أنت. من يقم أقم معه. ما احسن الصدق. كم عبيدلي. (والثاني) أن يقصر على الخبر نحو امما على شجاع وما عمروا لا مدبر. (والثالث) أن يلتبس بالفاعل نحو زيد فهم و كل إنسان لا يبلغ الحقيقة الشكر. (الرابع) أي يلتبس بالخبر نحو صديقك عدوى و أفضل منك أفضل

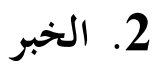

الخبر هو اسم مرفوع متحدث به، يقع غالبا

بعد المبتدأ، و قد يتقدم عنه، وبه يتم معنى الجملة. و قد تتعد الأخيار لمبتدأ واحد. 12 وقيل الخبر هو جزء الجملة الذي تتم به مع المبتدأ فائدة. و الأصل في الخبر أن يكون اسماً مفرداً، وقد يكون جملةً، أو شبه الجملة، سواء كانت الجملة فعلية أم اسمية أم شرطية. ولابد لجملة الخير من رابط يربطها بالمبتدأ، أي أن تشتمل على ضمير المبتدأ ظاهرا أو مقدرا، أو على اسم إشارة عائد الى المبتدأ، أو يعاد فيها المبتدأ بلفظه أو معناه، أو يكون فيها

2012 10ليمان فياض، النحو العصرى دليل مبسط لقواعد اللغة
الأقمار بالكثرة وعلر المحيطات بأنها خمس. ذالك الإسم يسمى (المبثدأ) والكلمة الأخرى تسمى

(خبر) المبتدأ وكلامها مرفوع. 10

وقد يقع البتدأ نكرة في الحالات الآتية: 1) (إذا كان موصوفا.

مثل:رجل كريم عندنا (المبتدأ: "رجل" نكرة لأنه موصوف) 2) إذا أضيف إلى نكرة.

مثل: طالب احسان (المبتدأ: "طالب" نكرة لأنه أضيف إلى نكرة)

$$
\text { 3) إذا سبقه نفي. }
$$

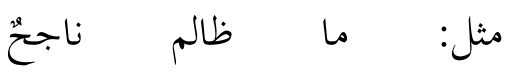
(المبتدأ:"ظالم"نكرة لأنه مسبوق

\section{بنفي)}

4) إذا سبقه استفهام.

مثل: هل رجلٌ فيكم (المبتدأ:

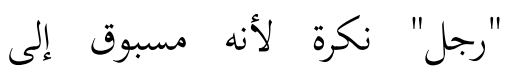

باستفهام) يحذف عادة المبتدأ من العناوين كعناوين الكتب والقصص و و الصحف...إلخ.

والأصل أن يتقدم المبتدأ على الخبر كما رأيت ويجوز أن يتأخر عنه نحو في الدار عليٌ و

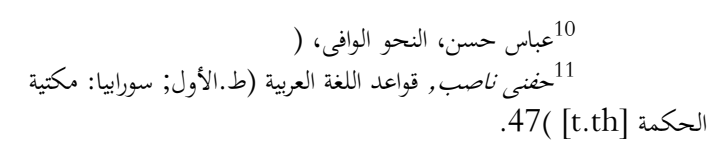


الآداب و الفضائل ، وتشريع الأحكام و القواعد ،

ولتضمنها الآية المشرقة وهي قوله تعالى :

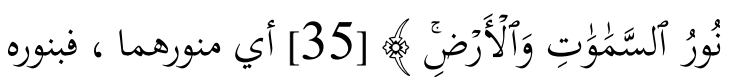
أضاءت السموات و الأرض ، وبنوره اهتدى الحيارى

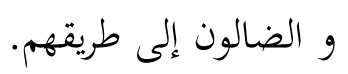
1 (1) مناسبتها لما قبلها.

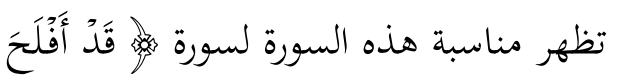

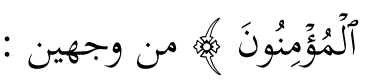

الأول، أنه تعالى لما قال في مطلع سورة

المؤمنين: ( والذين لفروجهم حافظون) ذكر هنا

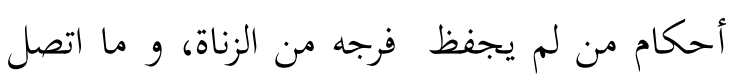
بذالك من شأن القذن ، وقصة الإفق، و الأمر بعض البصر الذي هو داعية الزنى، و الاستئذان الذي جعل من أجل النظر، و أمر بالتزويج حفظًا للفروج، و أمر من عجز عن مؤن الزواج بالاستعفاف و حفظ فرجه، و نهى إكراه الفتيات على الزنى. الثانى، بعد أن ذكر الله تعالى في سورة المؤمنين المبدأ العام في المسألة الخلق، وهو أنه لم يخلق الخلق عبثًا، بل للتكليف بالأمر و النهي، ذكر هنا طائفة من الأوامر و النواهي في أشياء تعد مزلقة للعصيان و الانحراف و الضلال. 2) فضلها

عموم يشمل المبتدأ، أو تكون جملة الخبر عين

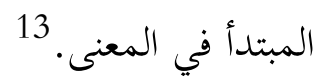

ويلزم تقديم الخبر في أربعة مواضع: (الأول) أن يكون من الألفاط التي لها الصدارة نحو أين أبوك و متى نصر الله. (والثاني) أن يقصر على المبتدإ نحو إنما الشجاع عليّ و مدبر إلا عمرو. (والثالث) أن يلتبس بالضمة نحو عندي درهم ولى حاجة. (والرابع) أن يعود على بعضه ضمير في المبتدإ نحو في الدار صاحبها أم على قلوب أقفالها. 14 وأما أقسام المبتدأ والخبر، هي:

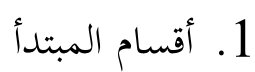

المبتدأ ثلاثة أقسام صريح، نحو:

"الكريم محبوب"، و ضمير منفصل، نحو: "أنت مجتهد"، مؤول، نحو: "وأن

تصوموا خير لكم". 15

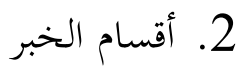

خبر المبتدأ ثلاثة أنواع : مفرد ، جملة و شبه الجملة.

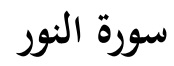
سورة النور هي سورة مدنية، من المثاني آياتها 64، و ترتيبها في المصحف 24، في الجزء الثامن عشر، نزلت بعد سورة الحشر. سميتها سورة النور لتنويرها طريق الحياة الاجتماعية للناس ، ببيان

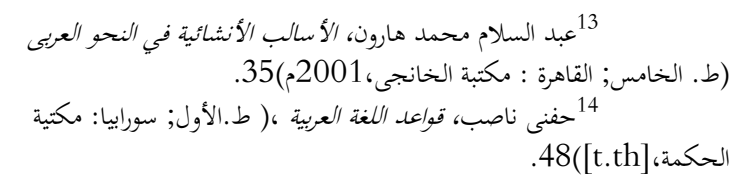


Al Bariq : Jurnal Pendidikan Bahasa Arab, 2, (1), 2021, 63-77

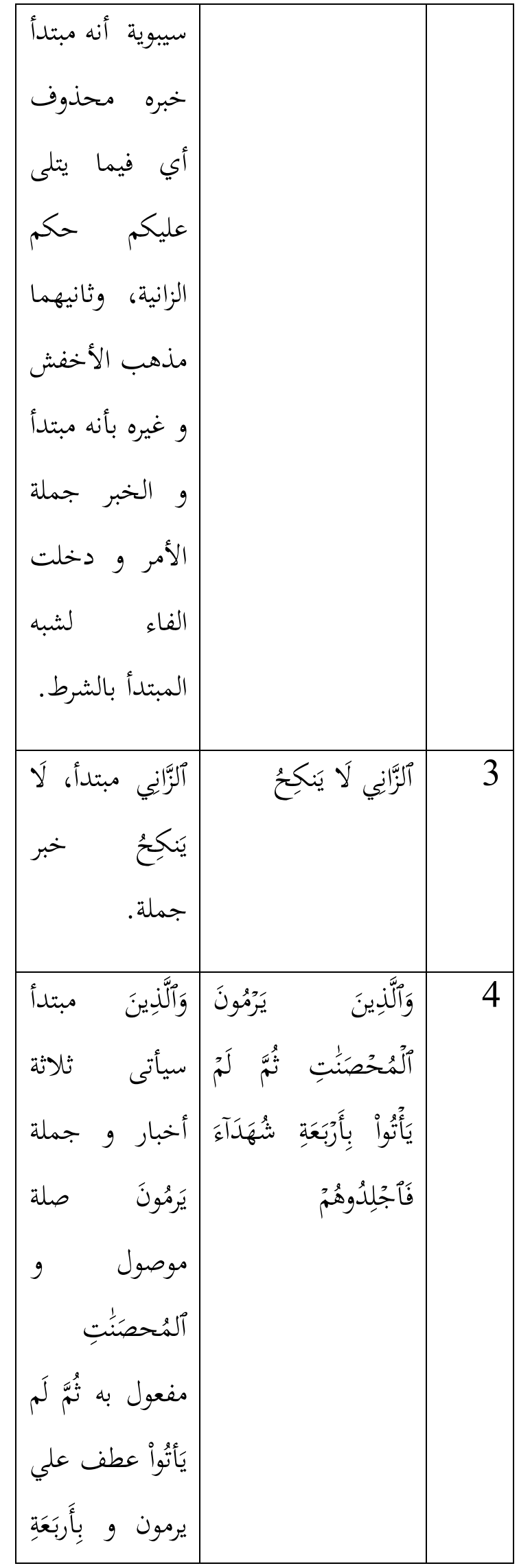

في هذه السورة أنس و شعور بالطمأنينة: لأن المؤمن يرتاح للعفة و الطهر، يشمئز من الفحش و سوء الظن و الاتهام، ذكر مجاهد أن رسول الله صل الله عليه و سلم قال: (علّموا رجالكم سورة المائدة و علموا نساءكم سورة النور ) وقال حارث بن مضرّب رضي الله عنه: كتب إلينا عمر بن الخطاب رضي الله عنه أن تعلّموا سورة النساء و الأحذاب و النور. و تغليم سورة للنساء مروي أيضا عن عائشة رضي الله عنها.

موقع إعراب الجملة الاسمية في سورة النور الجملة الاسمية أي الحملة التي تتكون من المبتدأ و الخبر في سورة النور كما يلي :

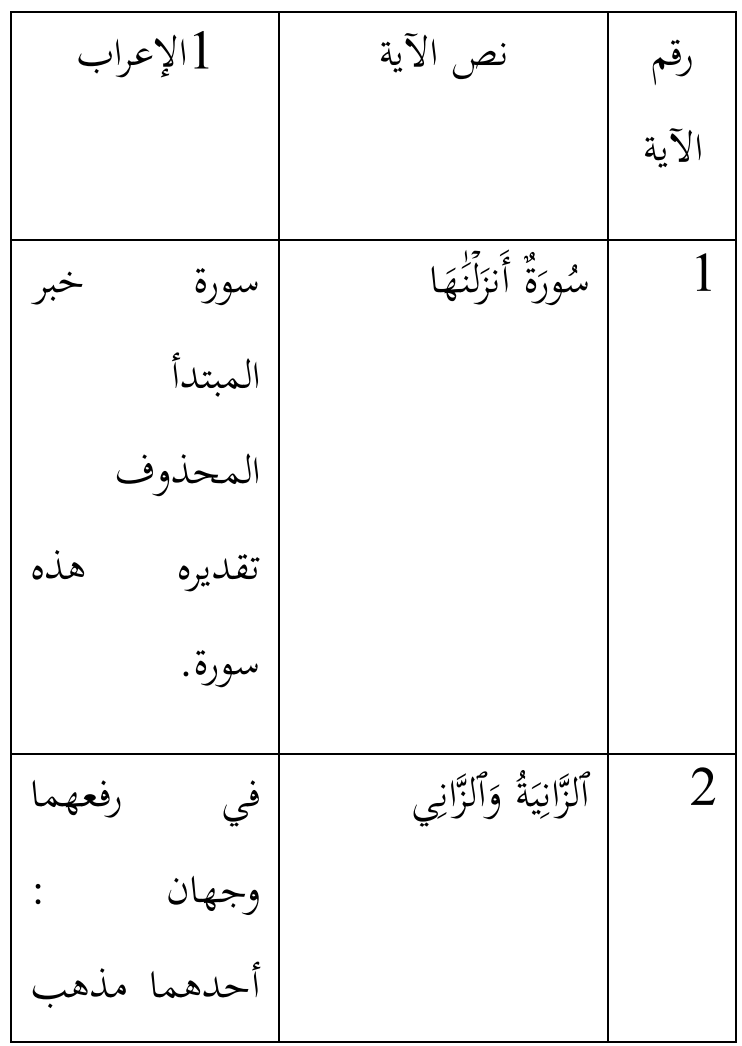


Al Bariq : Jurnal Pendidikan Bahasa Arab, 2, (1), 2021, 63-77
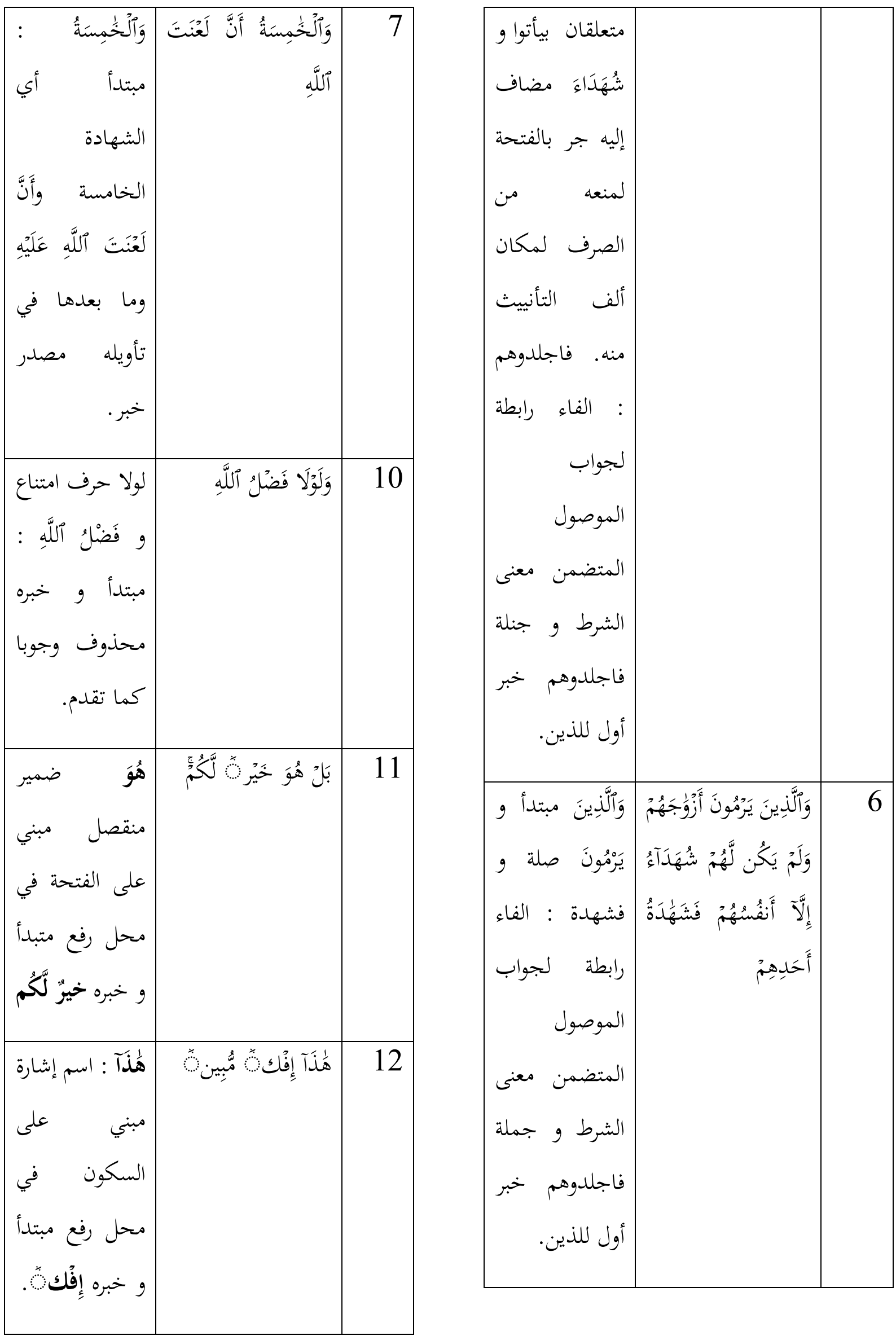
Al Bariq : Jurnal Pendidikan Bahasa Arab, 2, (1), 2021, 63-77

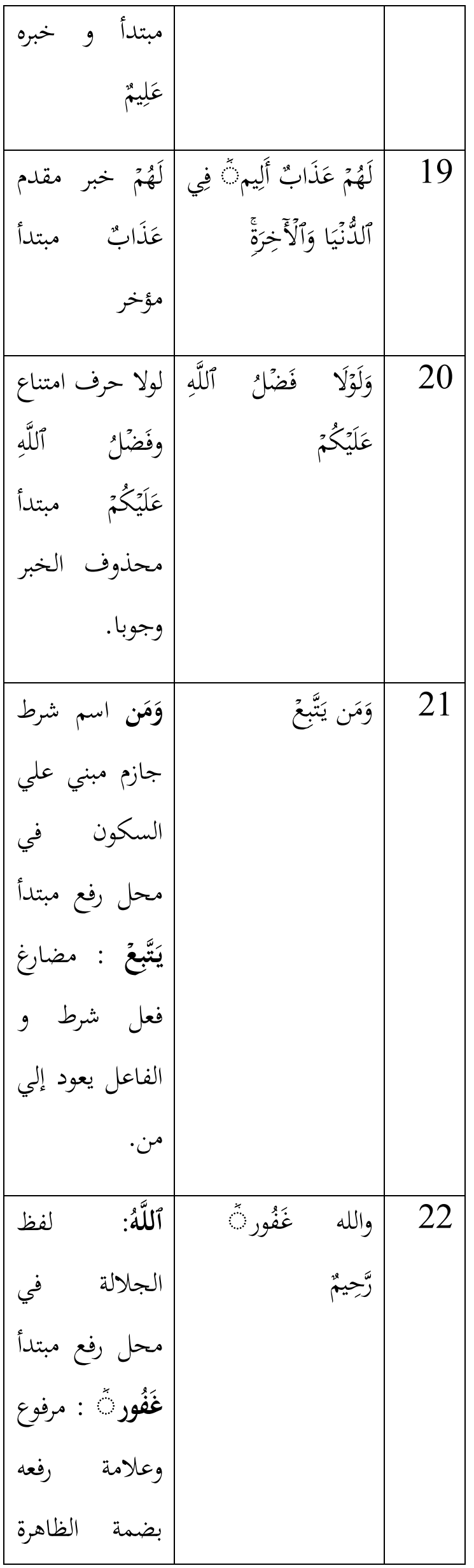

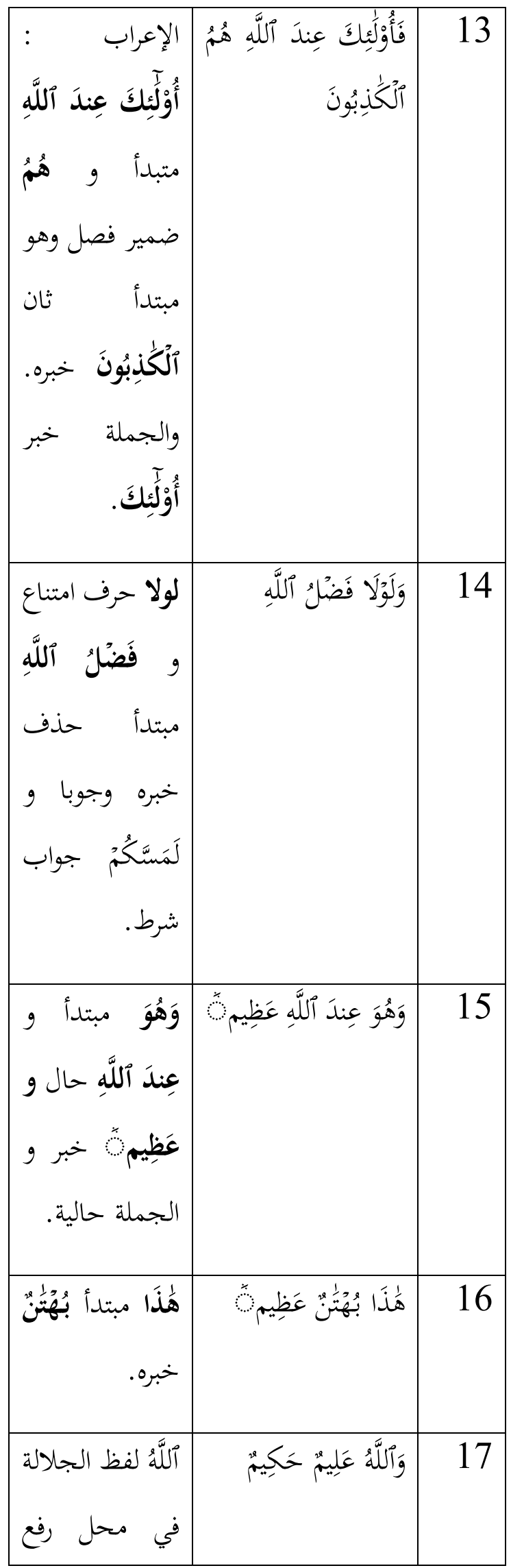


Al Bariq : Jurnal Pendidikan Bahasa Arab, 2, (1), 2021, 63-77

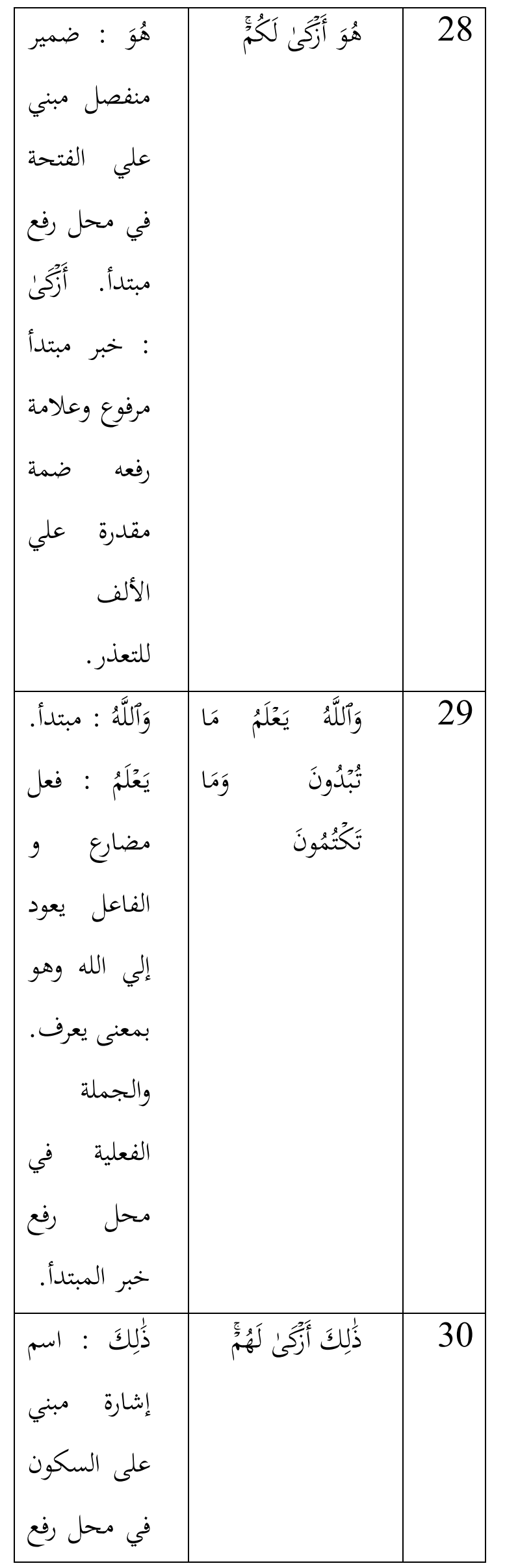

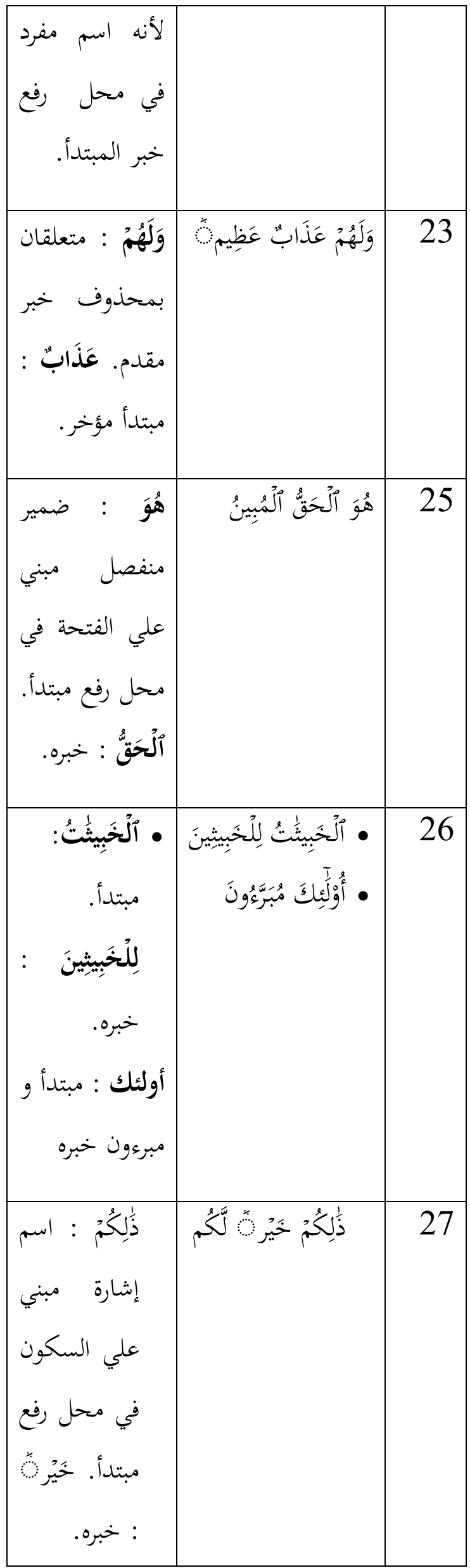


Al Bariq : Jurnal Pendidikan Bahasa Arab, 2, (1), 2021, 63-77

\begin{tabular}{|c|c|c|}
\hline مضاف وآلسَّمَوْتِ & & \\
\hline 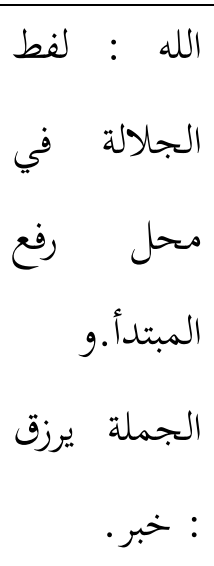 & وَألَلَّهُ يَرَزُقُق & 38 \\
\hline 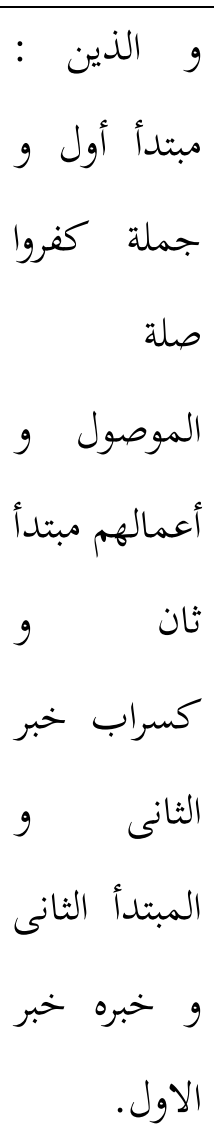 & 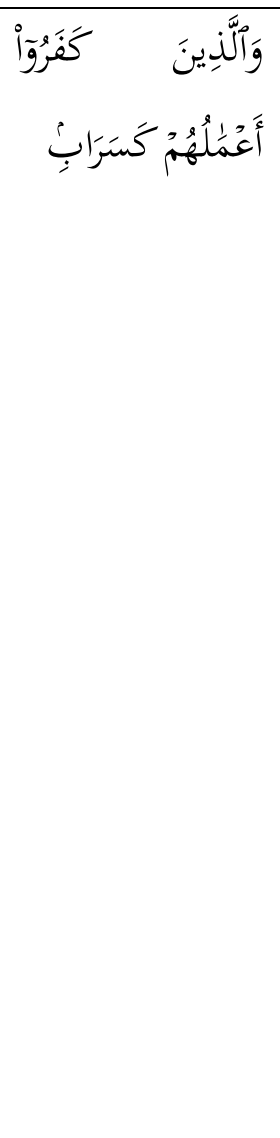 & 39 \\
\hline 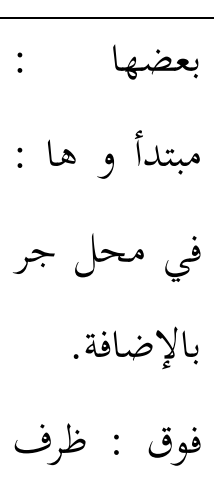 & 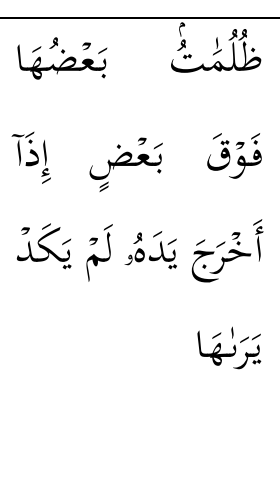 & 40 \\
\hline
\end{tabular}

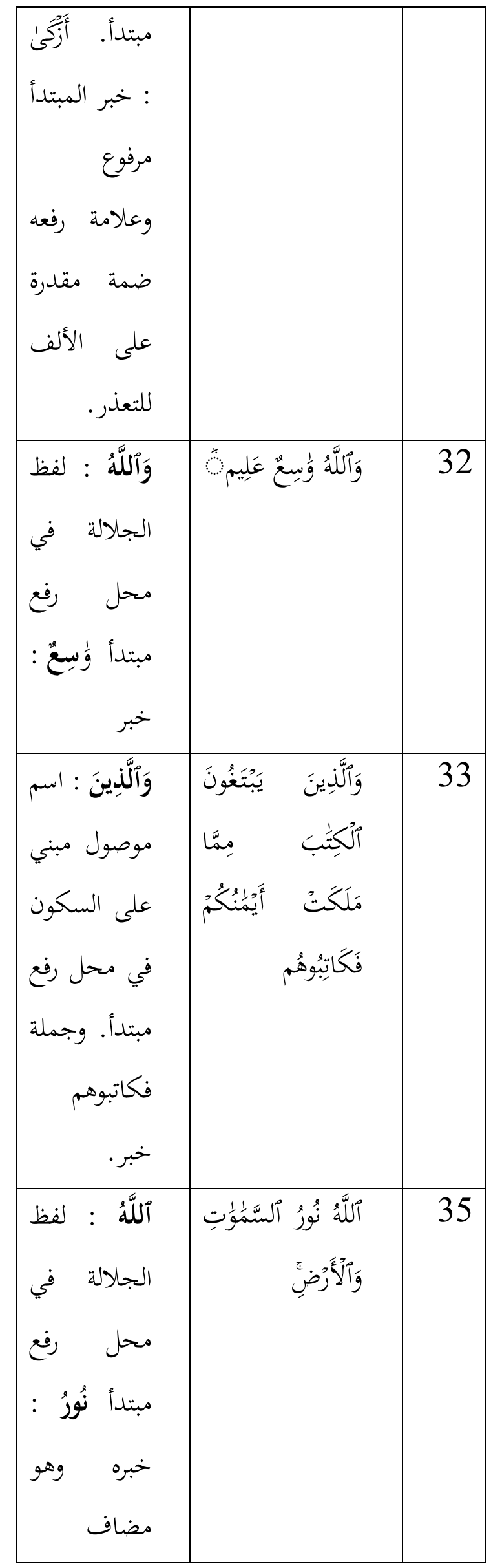


Al Bariq : Jurnal Pendidikan Bahasa Arab, 2, (1), 2021, 63-77

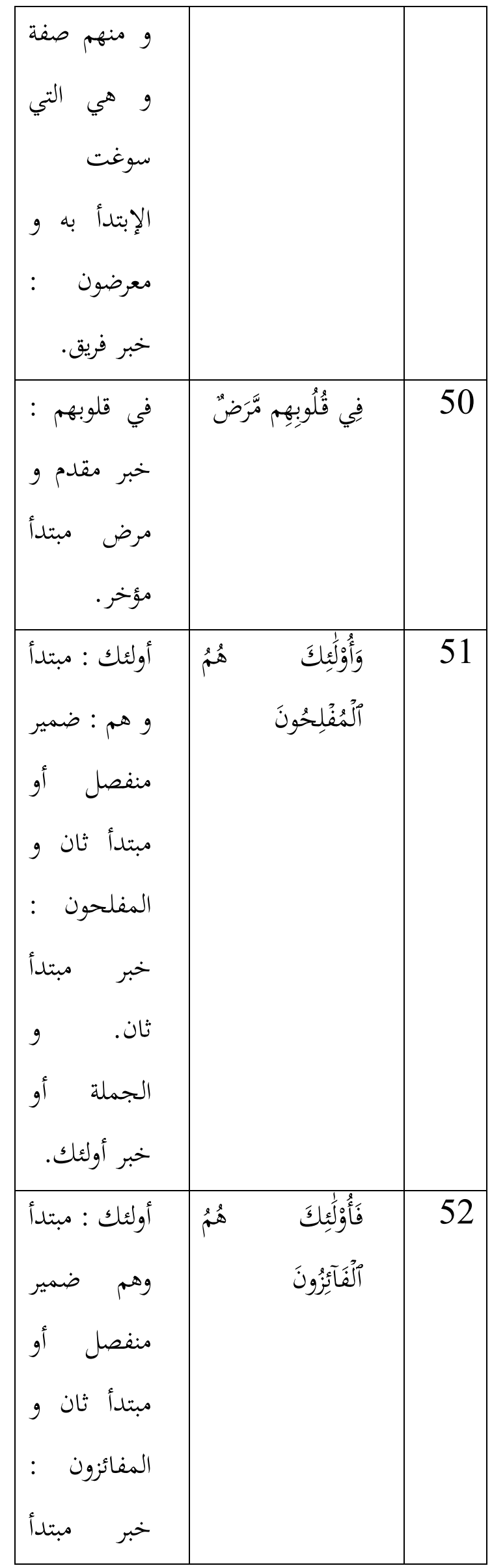

\begin{tabular}{|c|c|}
\hline مبحان متعلق & \\
\hline 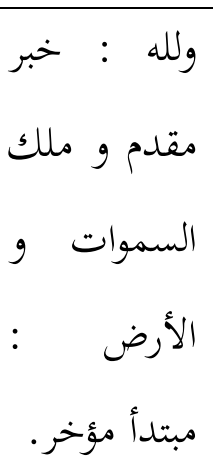 & وَلَِلَّهِ \\
\hline 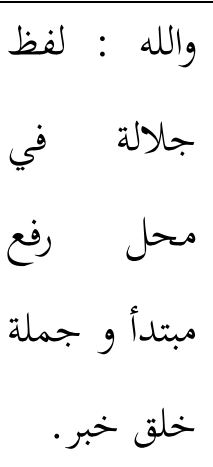 & 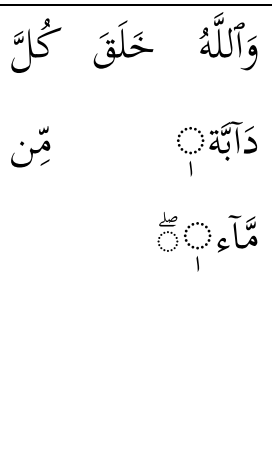 \\
\hline 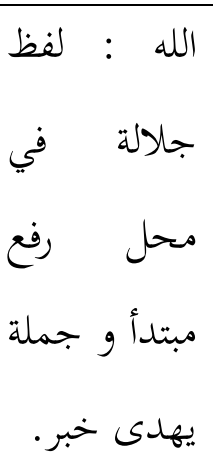 & وَآللَّلَه يَهُدِي \\
\hline 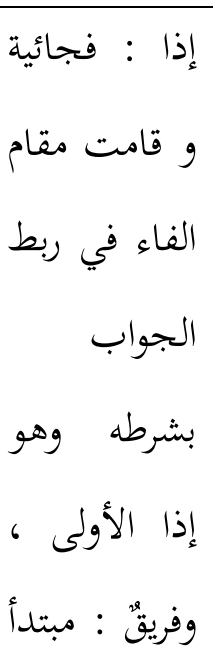 & 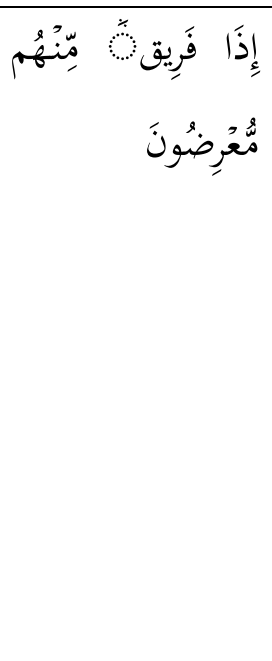 \\
\hline
\end{tabular}


Al Bariq : Jurnal Pendidikan Bahasa Arab, 2, (1), 2021, 63-77

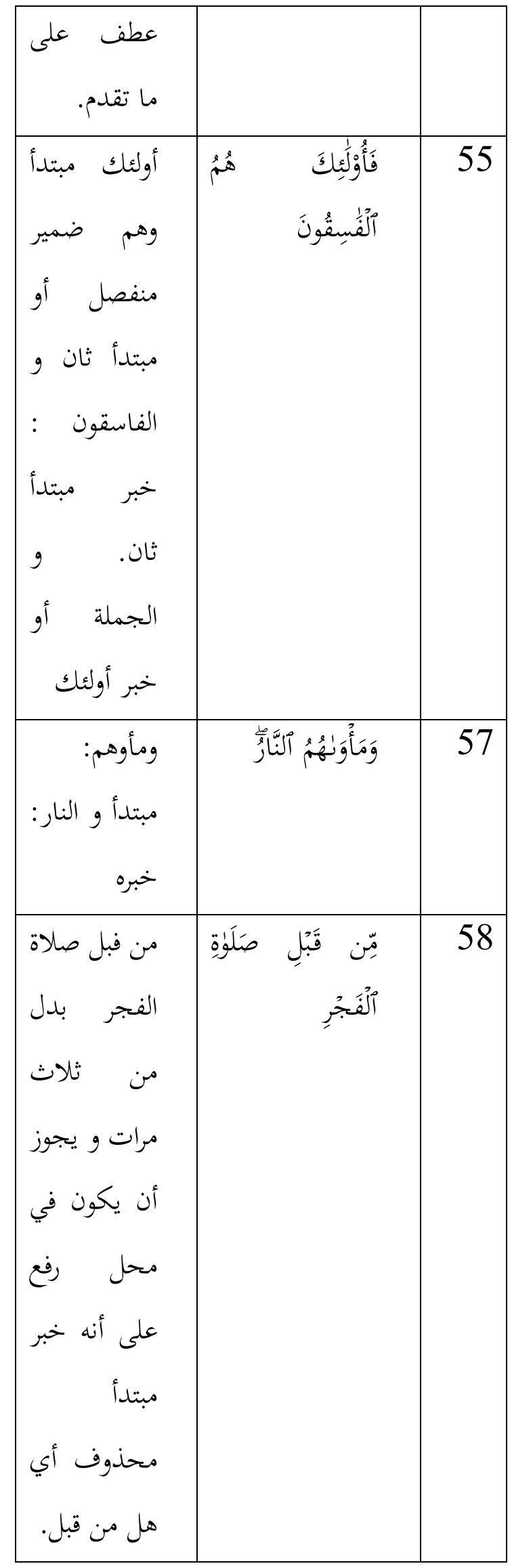

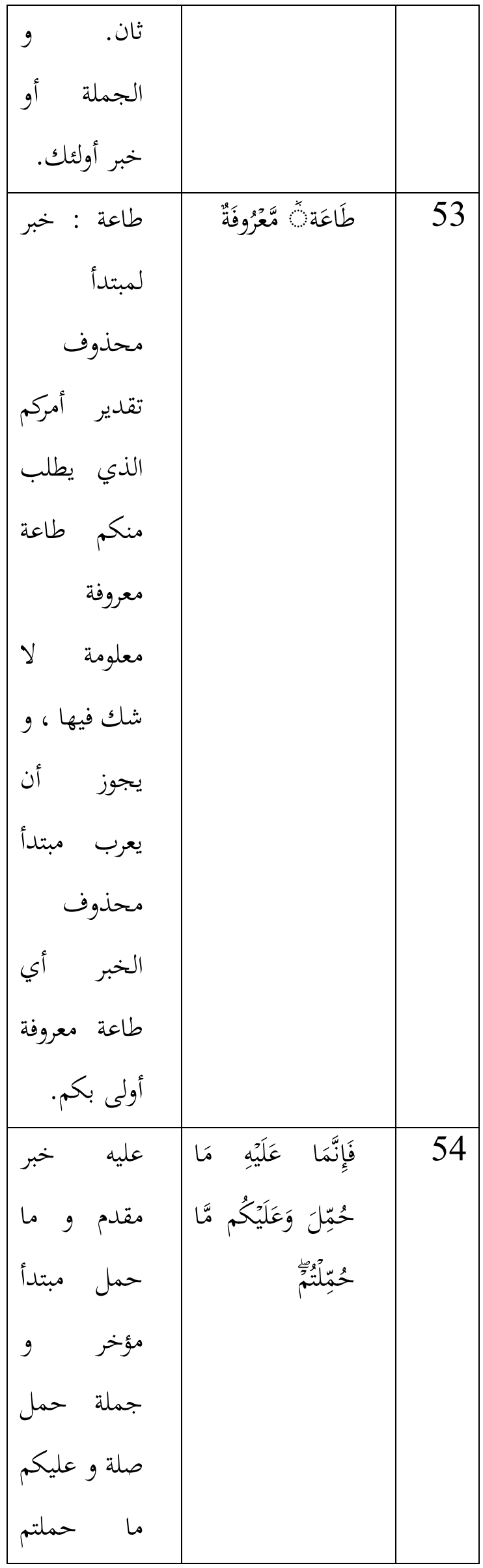


Al Bariq : Jurnal Pendidikan Bahasa Arab, 2, (1), 2021, 63-77

\begin{tabular}{|c|c|c|}
\hline 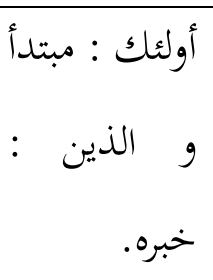 & 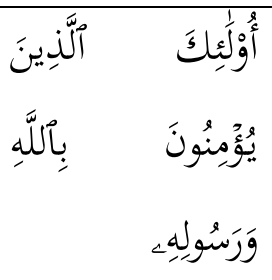 & 62 \\
\hline عليه خبره. & 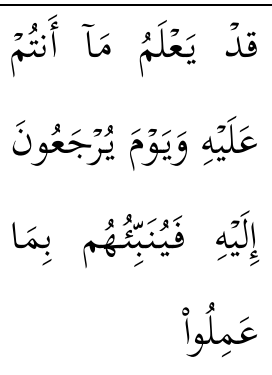 & 64 \\
\hline
\end{tabular}

الخلاصة

سورة النور هي سورة تتألف من أربع و

ستون آية، و تتضمن عن الجملة الاسمية التي كانت في بداية صيغة الأولى هي 48 آية. وهي في الآية

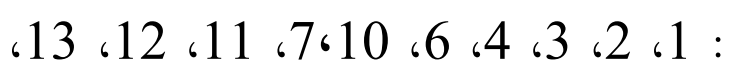

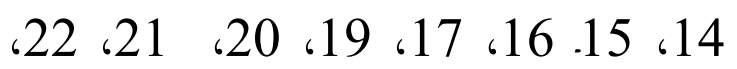
23، 25، 26، 32، 32، 28، 29، 29، 35، 38، 39، 40، 40، 45، 45، 45، 50 59، 60، 61، 62، 64. وفيها ثمانية و أربعون آية. وأما مبتدأ هو صريح خمسة و ثلاثون آيات، و منفصل ستة آيات، و مؤول واحد آية ، و أما خبر هو مفرد ثلاثة و عشرون آيات، و جملة ثلاثة عشرة آيات، و شبه الجملة ثلاثة آيات. و في كل آية من الآيات المذكورة إعراب يستعمل لتحليل الجملة الاسمية التي تتركب من المبتدأ و الخبر.

\begin{tabular}{|c|c|c|}
\hline مجلة مبلة & وَاَلَلَّهُ عَلِيمِ حَكِيم & 59 \\
\hline 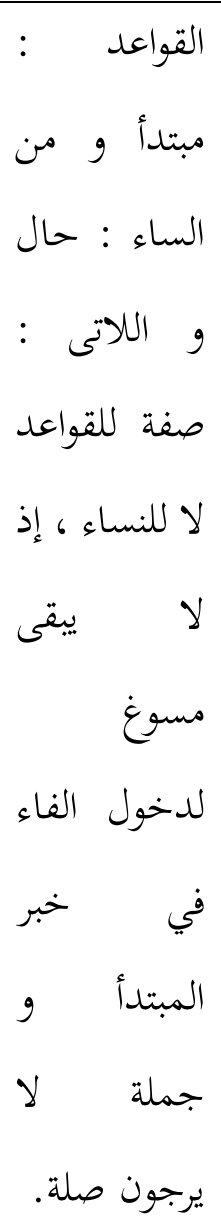 & 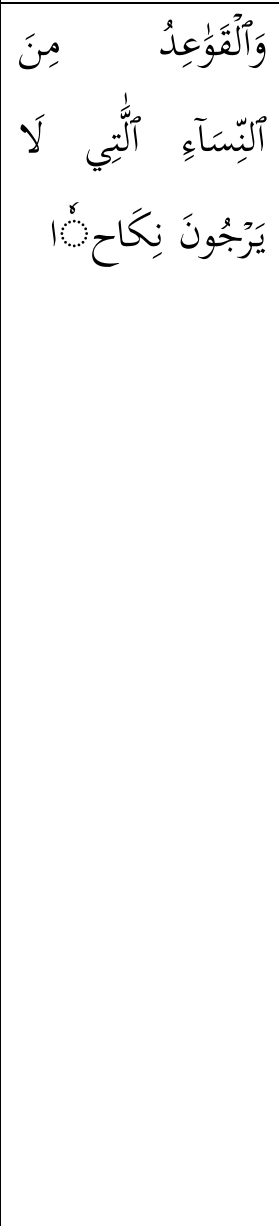 & 60 \\
\hline 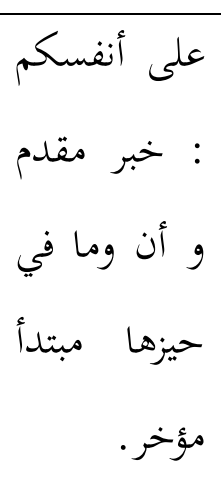 & 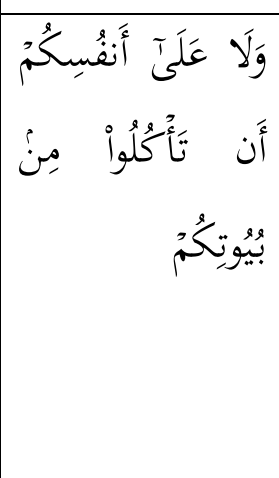 & 61 \\
\hline
\end{tabular}


الطاهر، ابن عاشور الشيخ محمد ، تنسير التحرير و

التنوير، الجزء الثامن عشر ؛ دار التونسية

للنشر

العمادى، أبى السعود محمد بن محمد ، تنسير أبى

السعود ، الجزء الخامس، ط. الثانية ؛

بيروت: دار الإحياء و التراث العبى،

1990

الجزائر، ابى بكر جابر ، /يسر الثغاسر ، المجلد الثاتى، ط. الرابعة ؛ الدراسة : الدار العالمية،

\section{3}

القطان، منّاع. مباحث في علوم القرآن. ط. الأولى؛ سورابايا: الهداية. 1973 م.

الجصاص، الإمام ابي بكر أحمد الرازي. احكام القرآن. ط. الأولى؛ مجلد. 1;بيروت: دار

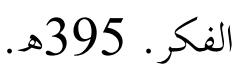

الغلاييني، شيح مصطفى. جامع الدوس اللغة العربية. ط. 30; جزء. 11;

منشورات المكتبة العصرية. 1993م.

الجارم، علي و أمين، مصطفى. النحو الواضح. ط. الجديدة; بيروت: المكتبة اللغوية.
الدينية، وزارة الشؤون. القرآن التجويد.ط.الأولى؛

بندوغ: ج ف فونوربيت ديفونيغارا.

2010

الدرة، لشيخ محمد علي طه ، تغسير القرآن الكريم

وأعرابه و بيانه ، المجلد التاسع؛ بيروت:

دار الحكمة، 1988 م. 1988 م.

ابي جعفر، محمد بن حسن الشيخ الطائفة ، التبيان في تنسير القران ، ط.الأولى، المجلد

السابع؛ مكتب الاعلام الاسلامى، 460-

. 385

الصبوني، محمد علي ، صغوة التغاسر، الملد الثاني؛

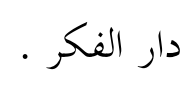

الزخشري، أبي قاسم جار الله محمود بن عمر ،

الكشاف، المجلد الثالث؛ دار الفكر،

.538-467

الزحيلي، وهبة ، تغسير المنير في العقائلد و الشريعة

و المنهج ، الجزء السابع عشر ؛ بيروت :

دار الفكر المعاصر، 1998 م.

المحلى، جلال الدين و السيوطى جلال الدين ، تغسير الجلالين ، دار التقوى. 
نعمة، فواد. ملخص قواعد اللغة العرابية. ط.الأولى؛ جزء. 19; بيروت: دار الثفافة الإسلامية.

\section{3}

محمد هارون عبد السلام. الأماليب الإنشائية في النحو العربى. ط. الأولى؛ القاهرة : مكتبة

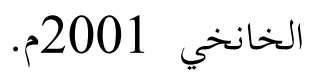

مكّى، بن أبي طالب القيس أبي محمد ،تغسير الهداية إلى البلوغ النهاية ، ط. الأولى؛ جامعة الشارقة ، 2008 م م.

ابن محمد عبد الله ابن مالك. الفية /بن مالك؛ سوربايا : توكو كتاب الهداية. ناصب، حفنى. قواعد اللغة العببية. ط.الأولى; سورابيا: مكتية الحكمة.

روصديانتو Jurus Kilat Menguasai Bahasa

Cet. I; Yogyakarta: Dilva Arab.

2016.Press

هارون محمد يحيى و ابو بكر بسلامة، Metode Mudah untuk Mempelajari Bahasa Arab dan Nahwu ; Yogyakarta:

CV.Bina Usaha, 1985),85.

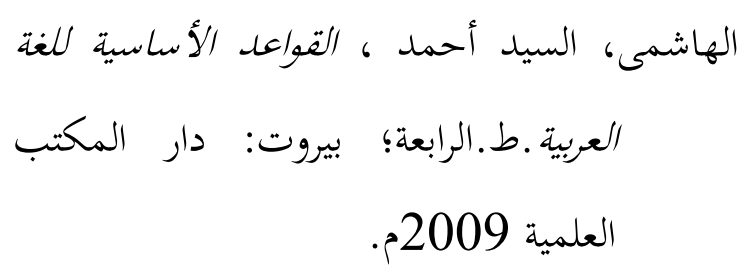

عبد العزيز عبده القلقية. معجم البلاغة العربية نفلد و تقص.ط.الأولى؛ القاهرة: دار الفكر العربية

\section{.1991}

عمر، أحمد مختار ـ التدريبات اللغوية و القواعد النحوية. ط. الثانية؛ كويت: مطبوعات

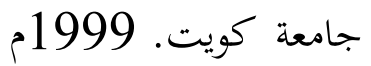


